Volume 3, Nomor 1, Maret 2021, pp 95-102. Copyright (C) 2019 JAFTA, Program Studi Magister Akuntansi, Fakultas Ekonomi, Universitas Kristen Maranatha. ISSN: 2654-4636 | E-ISSN: 2656-758X https://journal.maranatha.edu/index.php/jafta

\title{
PERSEPSI FAIRNESS ATAS SISTEM EVALUASI KINERJA
}

\author{
Oleh: \\ Adwita Harefa \\ Se Tin \\ Universitas Kristen Maranatha, Bandung \\ email: harefaadwita@gmail.com
}

\begin{abstract}
ABSTRAK
Tujuan studi ini adalah menjelaskan penerapan sistem evaluasi kinerja dan persepsi fairness terhadap sistem evaluasi kinerja pada perusahaan manufaktur, dagang dan jasa. Pengumpulan data menggunakan metode survei terhadap staf karyawan perusahaan yang tersebar di Sumatera, Jawa, Kalimantan, Sulawesi dan Papua. Sistem evaluasi kinerja merupakan komponen inti dari sistem pengendalian manajemen perusahaan. Hasil menunjukkan bahwa sistem evaluasi kinerja selalu menghubungkan kinerja karyawan dengan kinerja keuangan, dan kinerja non-keuangan. Hasil studi menunjukkan bahwa masih ada perbedaan persepsi di antara karyawan manufaktur, dagang, dan jasa terkait dengan keadilan prosedural (procedural fairness) terhadap sistem evaluasi kinerja. Hasil berimplikasi pada manajemen perusahaan agar mempertimbangkan sistem evaluasi kinerja yang fair untuk mengurangi konflik dan ketegangan serta meningkatkan rasa keadilan dan kepuasan karyawan dalam proses sistem evaluasi kinerja.
\end{abstract}

Kata Kunci: Sisten Evaluasi Kinerja, Persepsi Keadilan

\begin{abstract}
This study aims to determine performance evaluation system and fairness perception in performance evaluation system in manufacturing, merchandising and service business. The data acquisition was done using a survey method across company staffs over Sumatera, Java, Kalimantan, Sulawesi and Papua. Performance evaluation system is an essential component in a company's financial and non-financial performance. This study shows that there are still perception gaps among manufacturing, merchandising and service business regarding procedural fairness for performance evaluation system. The result suggests company managements to consider a fair performance evaluation system in order to minimize conflict and tension while increasing both sense of justice and employee satisfaction in performance evaluation.
\end{abstract}

Keywords: Performance Evaluation System, Fairness Perception

\section{PENDAHULUAN}

Semakin berkembang suatu industri semakin meningkat permintaan kebutuhan tenaga kerja profesional (Manopo, 2011). Perusahaan memahami bahwa dalam persaingan yang berubah secara terus menerus, sangat penting memantau kinerja perusahaan (Taticchi, 2010). Salah satu aspek penting dalam manajamen demi keberhasilan perusahaan yaitu melakukan 
evaluasi kinerja karyawan (Evita et.al 2017). Sistem evaluasi kinerja meningkatkan kualitas dan produktivitas dalam mencapai tujuan dan sasaran perusahaan. Sistem evaluasi kinerja memberikan penilaian terhadap hasil kerja yang diperoleh organisasi, tim, dan individu.

Dalam SeTin 2018, menguraikan perkembangan sistem evaluasi kinerja sebelum tahun 1980-an hingga tahun 2000. Ukuran sistem evaluasi kinerja yang digunakan oleh manajerial, diantaranya ukuran kinerja keuangan (produktivitas dan laba), ukuran kinerja non-keuangan (inovasi produk, kepemimpinan dan loyalitas pelanggan) serta sistem evaluasi kinerja yang semakin berkembang menggunakan ukuran kinerja relatif yang memfokuskan pada kinerja rekan. Nasution, 2020 dalam penelitiannya mengatakan bahwa penilaian yang objektif merupakan cara untuk menciptakan profesionalisme di dalam perusahaan. Atasan sering menghindari penilaian kinerja bawahannya karena khawatir dianggap tidak fair, dan subjektif (Manopo, 2011). Keadilan prosedural sangat penting karena dianggap mempengaruhi sikap dan komitmen anggota organisasi (Sholihin, et al., 2010). Agritansia et al., 2011, menyarankan perusahaan untuk melakukan pengukuran kinerja non keuangan untuk melengkapi pengukuran kinerja keuangan melalui procedural fairness. Di Indonesia belum ada studi khusus yang menyoroti tentang sistem evaluasi kinerja dan persepsi keadilan (fairness) pada perusahaan manufaktur, dagang dan jasa. Oleh karena itu, penelitian ini bertujuan untuk mendeskripsikan sistem evaluasi kinerja ditinjau dari ukuran keuangan, non- keuangan dan ukuran kinerja relatif serta persepsi fairness staf karyawan pada perusahaan manufaktur, dagang dan jasa.

\section{KERANGKA TEORITIS}

\section{Tinjuan Pustaka}

\section{Sistem Evaluasi Kinerja Keuangan}

Taticchi et al., 2010 mengatakan bahwa literatur sistem evaluasi kinerja mulai berkembang sebelum tahun 1980. Awalnya difokuskan pada ukuran kinerja keuangan tradisional seperti produktivitas, laba dan laba atas investasi (Latham, 1997) kemudian berkembang pada ukuran kinerja yang lebih prediktif. Ukuran kinerja keuangan memiliki keterbatasan relevansi yaitu tidak dapat mencerminkan kinerja perusahaan di masa mendatang (Chia et al., 2014) atau hanya mampu mencerminkan kinerja perusahaan saat ini dan kinerja masa di lalu. Penelitian terdahulu yang membahas tentang kinerja keuangan juga adalah Hoque et al. 2001 yaitu mengukur kemampuan perusahaan melalui strategi operating income, sales growth, dan return on investement. Sampai saat ini para peneliti memperdebatkan keunggulan jenis sistem 
evaluasi kinerja (SeTin, 2018).

\section{Sistem Evaluasi Kinerja Non Keuangan}

Ukuran kinerja keuangan yang terbatas dalam menghasilkan sistem pengukuran kinerja, memerlukan evaluasi bersifat non- keuangan. Balance Score Card telah menarik banyak perhatian dalam lima belas tahun terakhir dan telah diterapkan pada beberapa industri dengan sukses (Taticchi, 2010). Ada tiga perspektif ukuran kinerja non-keuangan menurut Kaplan dan Norton yaitu perspektif pembelajaran dan pertumbuhan (learning and growth perspective), perspektif proses bisnis internal (internal business process perspective) dan perspektif pelanggan (customer perspective).

Perspektif yang fokus pada pertumbuhan jangka panjang mencakup pelatihan, moral karyawan, tingkat turnover, tingkat kepuasan karyawan, dan adopsi teknologi dan inovasi baru yang diterapkan. Semua ini merupakan perspektif pembelajaran dan pertumbuhan. Keunggulan perusahaan juga ditentukan oleh kualitas proses bisnis internal, mencakup siklus produksi, tingkat persediaan, kualitas produksi, tingkat cacat output, dan waktu set-up. Kemudian, perspektif yang berfokus pada segmen pasar dan identifikasi target pelanggan meliputi jumlah pengiriman yang terlambat, jumlah keluhan pelanggan, waktu respon terhadap pelanggan, kepuasan pelanggan, dan jumlah pelanggan baru (Kaplan dan Norton, 1996).

\section{Sistem Evaluasi Kinerja Relatif}

Literatur pengukuran kinerja relatif menunjukkan beberapa definisi:

Kinerja relatif adalah ukuran kinerja yang menggunakan target yang disesuaikan dengan situasi aktual (pesaing dan faktor eksternal lain) selama periode tertentu (Bourmitrov dan Kaarboe 2013).

Kinerja relatif adalah sarana untuk menentukan standar kinerja dengan menggunakan patokan kelompok sejawat (Van Elten, 2017). Sebagai contoh, atasan membandingkan kinerja (manajer unit bisnis dalam organisasi yang sama). Kinerja rekan ini kemudian berfungsi sebagai target kinerja (tolak ukur) penilaian kinerja.

\section{Persepsi Procedural Fairness}

Dalam Agritansia dan Sholihin 2011 mengatakan teori keadilan prosedural pertama kali diperkenalkan oleh Thibaut et al., 1974. Keadilan prosedural juga digambarkan oleh Lind dan Tyler, 1988 pada penelitian terdahulu sebagai penilaian (judgements) tentang seberapa adil norma sosial yang terkait dan bagaimana orang diperlakukan serta bagaimana keputusan dibuat. Hasil penelitian Lind dan Tyler, 1988 menyatakan bahwa perusahaan dapat melihat kepuasan karyawan yang lebih besar, konflik yang minim dan keputusan 
terhadap prosedur ketika prosedur adil dalam suatu perusahaan. Kriteria keadilan menurut L\&T adalah:
1. Keakuratan dan kelengkapan informasi.

2. Retensi kontrol atas keputusan.

3. Ada jalan untuk memperbaiki keputusan yang tidak adil.

4. Mengadopsi / berorientasi pada

5. perspektif jangka panjang.

6. Mempertimbangkan kepentingan semua pihak.

7. Cara orang diperlakukan

Persepsi karyawan tentang seberapa adil prosedur evaluasi kinerja mereka, cenderung dipengaruhi oleh jenis ukuran dan bagaimana ukuran kinerja digunakan, serta persepsi mereka dibentuk oleh kewajaran dan prosedur yang digunakan dalam perusahaan (SeTin, 2018).

\section{METODE PENELITIAN}

Penelitian ini merupakan penelitian deskriptif. Data didapatkan dengan cara menyebarkan kuesioner pada level staf karyawan perusahaan. Sistem evaluasi kinerja menggunakan ukuran kinerja keuangan, non-keuangan dan ukuran kinerja relatif. Ukuran kinerja keuangan diukur dengan 6 item pertanyaan yaitu berkaitan dengan pendapatan operasional, pertumbuhan penjualan, keuntungan dari investasi, laba bersih, total biaya yang dikeluarkan, dan pendapatan perusahaan.
Sementara kinerja non-keuangan diukur dengan 17 item pertanyaan untuk perusahaan manufaktur, 11 item pertanyaan untuk perusahaan dagang, dan 6 item pertanyaan untuk perusahaan jasa (disesuaikan dengan proses bisnis internal perusahaan). Kinerja non-keuangan diukur dengan periode waktu antara pemesanan pelanggan dan pesanan selesai dikerjakan, kerugian yang timbul selama proses produksi, efisiensi tenaga kerja, efisiensi penggunaan bahan baku, banyaknya produk cacat, banyaknya produk berkualitas dari total barang yang diproduksi, jumlah hak paten baru perusahaan, jumlah produk baru yang dikeluarkan, waktu untuk meluncurkan produk baru ke pangsa pasar, keberhasilan menembus pasar dibandingkan pesaing, ketepatan waktu dalam mengantar pesanan, jumlah komplain dari pelanggan, kepuasan pelanggan, biaya perbaikan garansi, respon pelanggan berkaitan dengan waktu dalam menyelesaikan pesanan, siklus waktu dari pemesanan sampai barang diterima pelanggan dan persentase pengembalian barang karena cacat. Kinerja relatif diukur dengan 3 item pertanyaan yaitu kinerja rekan, kemudian kinerja rekan saat kinerja karyawan lebih baik dan saat kinerja karyawan lebih buruk.

Sampel adalah bagian dari jumlah dan karakteristik yang dimiliki oleh populasi (Sugiyono, 2014). Berdasarkan pengertian 
tersebut, maka yang menjadi sampel dalam penelitian ini yaitu 150 orang staf karyawan dari 15 perusahaan, masing-masing 5 dari perusahaan manufaktur, 5 dari perusahaan dagang, dan 5 dari perusahaan jasa.

Pengambilan sampel pada penelitian ini dilakukan dengan teknik nonprobability sampling. Menurut Sugiyono (2014), nonprobability sampling adalah teknik pengambilan yang tidak memberi kesempatan sama bagi setiap unsur atau anggota populasi untuk dipilih menjadi sampel. Berdasarkan pengertian di atas, peneliti memilih anggota populasi yang dapat memberikan informasi maksimal yang dibutuhkan untuk penelitian ini yaitu staf karyawan dibawah level manajer.

\section{HASIL PENELITIAN DAN PEMBAHASAN}

Penelitian dilakukan dengan cara menyebarkan kuesioner dalam bentuk google form masing-masing 50 kuesioner pada perusahaan manufaktur, perusahaan dagang, dan perusahaan jasa. Dengan memanfaatkan teknologi internet penulis mampu memperoleh data subjek penelitian yang mewakili setiap provinsi yaitu Sumatera, Jawa, Kalimantan, Sulawesi dan Papua.

Berdasarkan hasil yang diperoleh mayoritas responden dari perusahaan manufaktur adalah wanita. Mayoritas responden yang diperoleh dari perusahaan dagang adalah pria. Sementara pada perusahaan jasa jumlah responden pria dan wanita adalah seimbang masing-masing 25 orang.

Dalam penelitian ini status pendidikan responden dikelompokkan menjadi empat bagian yaitu D3, S1, S2 dan S3. Berdasarkan pengelompokkan tersebut, dari ketiga jenis perusahaan mayoritas responden memiliki status pendidikan S1 dan paling sedikit responden dengan status pendidikan S3 yaitu pada perusahaan manufaktur berjumlah satu orang.

Mayoritas responden yang diperoleh memiliki masa kerja kurang dari lima tahun. Pada penelitian ini usia dikelompokkan menjadi empat bagian berdasarkan umur produktif seseorang bekerja. Mayoritas responden berusia 18 sampai dengan 25 tahun. 
Tabel 1. Hasil Kuesioner

Sistem Evaluasi Kinerja

\begin{tabular}{cccc}
\cline { 2 - 4 } Perusahaan & Kinerja Keuangan & $\begin{array}{c}\text { Kinerja Non- } \\
\text { Keuangan }\end{array}$ & Kinerja Relatif \\
\hline Manufaktur & Selalu Penting & Selalu Penting & Selalu Penting \\
Dagang & Selalu Penting & Selalu Penting & Biasanya Penting \\
Jasa & Selalu Penting & Selalu Penting & Selalu Penting \\
\hline
\end{tabular}

Pada tabel 1 dapat dilihat bahwa dagang biasanya penting, artinya ukuran ukuran kinerja keuangan dan non- keuangan kinerja rekan rutin tetapi tidak konsisten selalu penting. Hal ini merepresentasikan ukuran kinerja yang konsisten atau tidak (90\%) dihubungkan oleh atasan saat melakukan evaluasi kinerja karena yang pernah tidak dihubungkan oleh atasan saat melakukan evaluasi kinerja. Sedangkan menjadi fokus perusahaan dagang adalah target penjualan.

ukuran kinerja rekan pada perusahaan

Tabel 2. Hasil Kuesioner

\section{Perusahaan}

Manufaktur

Dagang

Jasa

\section{Persepsi Fairness atas Sistem Evaluasi} Kinerja

\begin{tabular}{cc}
\hline Manufaktur & Setuju \\
Dagang & Sangat Setuju \\
Jasa & Setuju \\
\hline
\end{tabular}

Pada tabel 2 dapat dilihat persepsi fairness staf karyawan terhadap sistem evaluasi kinerja tiga jenis perusahaan yaitu manufaktur, dagang dan jasa.

\section{SIMPULAN DAN SARAN}

Penelitian ini menunjukkan bahwa masih ada perbedaan persepsi antara staf karyawan manufaktur, dagang dan jasa terkait dengan keadilan prosedural (procedural fairness) atas sistem evaluasi kinerja. Sistem evaluasi kinerja dari ketiga jenis perusahaan ini selalu menghubungkan penilaian kinerja karyawan dengan kinerja keuangan dan non-keuangan. Dari hasil yang diperoleh untuk ukuran kinerja relatif, 
pada perusahaan manufaktur dan jasa atasan selalu menghubungkan kinerja rekan saat melakukan evaluasi kinerja sementara pada perusahaan dagang kinerja rekan (relatif) tidak selalu dihubungkan oleh atasan karena pada perusahaan dagang target penjualan merupakan tolak ukur saat melakukan evaluasi kinerja. Persepsi staf karyawanan manufaktur dan jasa adalah setuju terhadap sistem evaluasi kinerja yang fair, sementara pada perusahaan dagang persepsi staf karyawan adalah sangat setuju terhadap sistem evaluasi kinerja yang adil.

Untuk perusahaan hasil berimplikasi pada manajemen agar mempertimbangkan sistem evaluasi kinerja yang fair agar mengurangi konflik dan ketegangan serta meningkatkan rasa keadilan dan kepuasan karyawan dalam proses evaluasi kinerja.

$$
\text { Bagi penelitian selanjutnya }
$$
sebaiknya menggunakan sampel lebih banyak dengan keragaman karakteristik yang berbeda dan mengembangkan ukuran evaluasi kinerja sehingga dapat meningkatkan sistem evaluasi kinerja yang lebih unggul.

\section{DAFTAR PUSTAKA}

Agritansia, Putri Paramita, and Mahfud Sholihin. (2011). "The Attitudinal and Behavioral Effects of Nonfinancial Measures.”Gadjah Mada International Journal of Business 13(3): 267.
Bourmistrov, A. and Kaarboe, K. (2013).

"From comfort to stretch zones: a field study of two multinational companies applying 'Beyond budgeting' ideas." Management Accounting Research, 24 (3) : 196211.

Chia, D.P.S; Lau, C.M., and Tan, S.L.C. (2014). "The relationship between perfomance measurement and employee Outcomes: The mediating roles of procedural fairness and trust, in Davila, A., Epstein, M. J., and Manzoni, J.F. (ed). Performance Measurement and Management Control: Behavioral Implication and Human Actions (Studies in Managerial and Financial Accounting, Volume 28) Emerald Group Publishing Limited, pp.203 232

Evita, Siti Noni, Wa Ode Zusnita Muizu, and Raden Tri Wahyu Atmojo. (2017). "Penilaian Kinerja Karyawan Dengan Menggunakan Metode Behaviorally Anchor Rating Scale Dan Management By Objectives (Sudi Kasus Pada PT Qwords Company International)." Pekbis Jurnal 9(1): 18-32.

Hoque,Z.,L. Mia, and M. Alam. (2001). Market Competition, computeraided manufacturing and use of multiple performance measures: An 
empirical study. British Accounting Review 33: 23-45.

Kaplan, R. S., and D. P. Norton. (1992). The balanced scorecard: Measures that drive performance. Harvard Business Review (JanuaryFebruary): 71-79.

Latham, G.P. and Seijts, G.H. (1997). "The Effect of Appraisal Instrument on Managerial Perception of Fairness and Satisfaction with Appraisals from their Peers. Canadian Journal of Behavioral Science, 29, 275-282.

Lind, E.A. and T.R. Tyler. (1988), The Social Psychology of Procedural Justice (Plenum Press, New York).

Manopo, Christine. (2011). “Competency Based Talent And Performance Management System". (4) : 2-73.

Nasution, Sri Rezeki. (2020). "Sistem Pendukung Keputusan Penilaian Dan Evaluasi Terhadap Kinerja Karyawan Dengan Metode Preference Selection Index ( PSI ) Pada Industri Primer Pengolahan Kayu UD Maju Rezeki.” :383-91.

SeTin. (2018). "Hubungan Sistem Evaluasi Kinerja dan Budget Gaming Behaviour melalui Persepsi Organizational Politics dan Persepsi Procedural Fairness."

Sholihin, Mahfud, and Richard Pike. (2010). "Organisational Commitment in the Police Service: Exploring the Effects of Performance Measures, Procedural Justice and Interpersonal Trust." Financial Accountability \& Management 26(4): 392-421.

Sugiyono. (2014). "Metodologi Penelitian Bisnis: Pendekatan, Kualitatif, dan R\&D”.

Taticchi, Paolo, Flavio Tonelli, and Luca Cagnazzo. (2010). "Performance Measurement and Management: A Literature Review and a Research Agenda." Measuring Business Excellence 14(1): 4-18.

Thibaut,J.,N. Friedland and L. Walker (1974), "Compliance with Rule: Some Social Determinants, Journal of Personality and Social Psychology, Vol. 30, pp. 782-801.

Van Elten, H.J. (2017). "Relative Performance Evaluation amongst Business Unit Level Managers", Accounting Research Journal, 30 (2): $185-204$ 